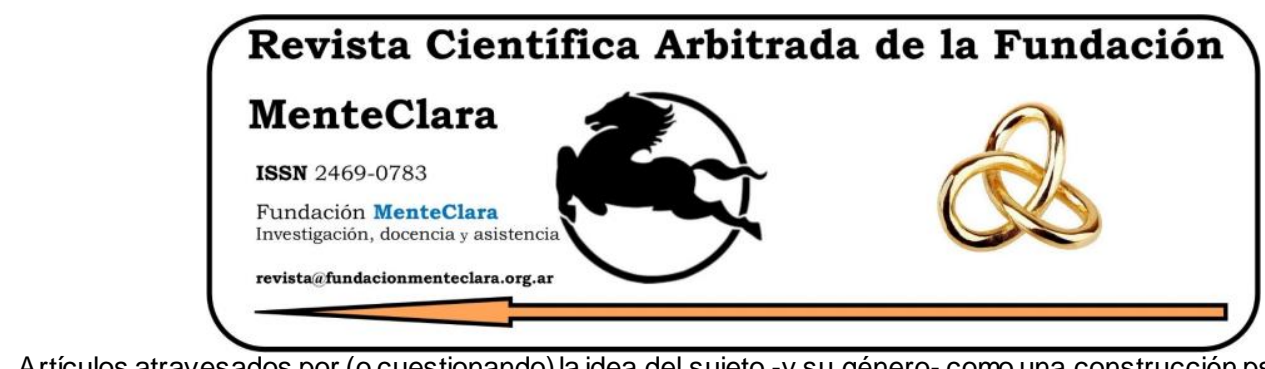

Artículos atravesados por (o cuestionando) la idea del sujeto -y su género- como una construcción psicobiológica de la cultura. Articles driven by (or questioning) the idea of the subject -and their gender- as a cultural psychobiological construction.

Vol. 7 (2022), enero-diciembre ISSN 2469-0783

https: / / datahub.io/ dataset/2022-7-e263

\title{
EMANCIPACIÓN TEÓRICA DE LA PRÁCTICA CONTABLE, COMO TÉCNICA PARA EL CUMPLIMIENTO DE LOS OBJETIVOS DEL DESARROLLO SOSTENIBLE - ODS
}

\author{
THEORETICAL EMANCIPATION OF THE ACCOUNTING PRACTICE, AS A \\ TECHNIQUE FOR THE FULFILLMENT OF THE SUSTAINABLE DEVELOPMENT \\ GOALS - ODS
}

Claudia E. Amézquita Medina Claudia.amezquita@uptc.edu.co Universidad Pedagógica y Tecnológica de Colombia, Programa de Contaduria Pública, Sede Seccional Sogamoso, Colombia.

Cómo citar este artículo / Citation: Amézquita, C. (2022). Emancipación teórica de la práctica contable, como té cnica para el cumplimiento de los Objetivos de Desarrollo Sostenible - ODS. Revista Científica Arbitrada de la Fundación MenteClara, Vol. 7 (263). DOI: https://doi.org/10.32351/rca.v7.263

Copyright: (C) 2022 RCAFMC. Este artículo de acceso abierto es distribuido bajo los términos de la licencia Creative Commons Attribution 4.0 International License (CC BY 4.0). Recibido: 18/01/2022. Aceptado: 03/02/2022 Publicación online: 11/02/2022

Conflicto de intereses: Ninguno que declarar.

\section{Resumen}

Se pretende una conciliación paradigmática como mecanismo regulador entre las intersubjetividades que se generan a partir de la aplicación de normas internacionales de información financiera, que permitan garantizar informes de alta calidad ética, aplicando métodos científicos que den fe pública del bien común y de la sostenibilidad de la vida en un planeta sano, libre de corrupción.

El método empleado para el desarrollo subyace al análisis etnográfico que ha de realizarse sobre un número indeterminado de prácticas empresariales, donde se ponen a prueba los prototipos de los registros contables, para dar cumplimiento a los ODS. 


\section{Abstract}

A paradigmatic conciliation is intended as a regulatory mechanism of the intersubjectivities that are generated from the application of international financial reporting standards, to guarantee reports of high ethical quality, applying scientific and ethical methods that give public faith of the common good and sustainability. of life on a healthy planet, free from corruption. The method used for its development underlies the ethnographic analysis that has to be carried out on an indeterminate number of business practices, where the prototypes of the registries are tested, in order to comply with the SDGs.

Palabras Claves: Bien común; Emancipación contable; Etnografia; Neopatrimonialismo; ODS

Keyw ords: Common good; accounting emancipation; Ethnography; Neopatrimonialism; SDGs 


\section{Introducción}

En Colombia la normatividad educativa le exige al docente atender resultados de aprendizaje en donde el estudiante adquiera las habilidades disciplinares para toda la vida, construidos estos, sobre una evidencia real de logros, encaminados hacia una formación integral y a un desarrollo pleno y auténtico del ser contable, en donde se integren las particularidades de su esencia como "ser", con lo normativo positivista de su "hacer" y con lo loable del "saber" contable; es decir, se hace indispensable que la labor pedagógica se centre en responder de forma filosófica y científica, un cuestionamiento profundo sobre el devenir de un ser que ha de representarse, representar e interpretar los fenómenos económicos, ambientales y sociales, dando fe pública del Bien Común.

El trabajo de investigación se postula, bajo esta labor pedagógica y filosófica de la disciplina contable, como aspirante al doctorado en Ciencias Contables ante la Universidad de los Andes de Mérida, Venezuela. Así mismo, servirá de apoyo académico dentro del plan de acción resultante de la autoevaluación con fines de acreditación, según el Decreto 1330 de 2019; el cual se viene implementando en el programa de Contaduría Pública de la Universidad Pedagógica y Tecnológica de Colombia, en su Sede Seccional Sogamoso, desde el año 2021.

Tanto el enfoque como los instrumentos metodológicos necesarios en el recorrido argumentativo, antes, durante y después de la postulación de la tesis, se definen para dar respuesta al siguiente cuestionamiento: ¿Es posible que la contabilidad pueda ejercer un poder emancipador que supere las fuerzas positivistas que la reducen o, la atomizan en su función de informar; para pasar a ser una ciencia universal del bien común, que garantice la sostenibilidad de la vida en el planeta, evitando la corrupción? 
Al iniciar un recorrido por el acervo bibliográfico, con el afán de encontrar coincidencias conceptuales entre teorias y corrientes de pensamiento que sirvan de fuente argumentativa para la defensa de la tesis, y que, también ayuden a definir el enfoque investigativo, sus métodos y sus instrumentos, nos aparece la corriente neo patrimonialista, de manera recurrente.

El libro recién publicado por los doctores Rafael Franco Ruíz, Jesús Alberto Suárez Pineda, Valerio Nepomuceno, Rodrigo Antonio Chaves Da Silva, Vanessa Cano Mejía, y Juan David Arias Suárez, titulado "Antonio Lopes de Sá, filósofo de la contabilidad", expone los postulados para el análisis de la funcionalidad o la validez de las categorias y sus relaciones semánticas, epistémicas y ontológicas de la "Teoria contábil da socialidade e contabilidade social(constructos lógicos gerais e específicos)" (2008), artículo en el que Lopes de Sá reconoce una octava función: la eficacia social (socialidade), sugerida por Valério Nepomuceno, y que servirá para equipararla con el Bien Común.

La corriente patrimonialista es la que destaca como objeto de estudios de la contabilidad al patrimonio (Martínez, 2014). Que, para efectos de la tesis, se equiparará con el Bien Común; ya que, en el neo patrimonialismo la ciencia contable tiene como objeto un movimiento de masas patrimoniales, expresadas en tres fuentes: 1) patrimonio económico, 2) patrimonio socio-cultural y 3) patrimonio humano.

Es decir, la comprensión, entendimiento y explicación de esos movimientos es su razón de ser. La argumentación para la tesis, se centra en su equivalencia de la comprensión con el bien común representado en la eficacia social del total del patrimonio.

En este orden de ideas, el fenómeno patrimonial se define como una acción esencial de las formas de vida en el planeta, a saber: la necesidad 
o la carencia que hace producir el fenómeno celular orgánico, la finalidad o razón del fenómeno, el medio o riqueza material que utiliza dentro y fuera de la célula orgánica, en su función de satisfacer o reprimir eficazmente dichas necesidades. Así, el bien común, se equiparará con esta definición de patrimonio; ya que todo fenómeno patrimonial, tendrá como fin último, la eficaz atención de necesidades de la vida misma; es decir, asegurar el bien común.

En este empeño, subyace la teoría del patrimonio, como la riqueza indispensable para satisfacer las necesidades de la humanidad.

El planteamiento inicial de la tesis, se apoya en Lopes de Sá en su fundamento, o postura critico social heterodoxa, acudiendo a la estructura del pensamiento y del conocimiento contable, que ha de ostentar el contador público.

El presente trabajo, pretende el análisis y monitoreo de variables independientes y dependientes, de y para la eficacia empresarial y profesional, con base en un registro integrado; todo esto, para confirmar la validez de la hipótesis que demostraría qué: la aplicación eficaz y ética de un registro contable que integre la totalidad de los objetivos de la contabilidad como ciencia del bien común, podrá asegurar la eficacia personal, empresarial y social, dando cumplimiento a los objetivos para la sostenibilidad de la vida en el planeta.

En busca de efectos unificadores, en torno a la sostenibilidad de la vida en el planeta, se centrará el trabajo indagatorio inicial, en la identificación de las variables del registro contable, en función del cumplimiento de los ODS, bajo un enfoque neo patrimonial, que permite orientar el recorrido metodológico de la tesis, en consonancia con una postura filosófica en el autor Lopes de Sá, cuyo mayor afán es encontrar la eficacia social; en el bien común. 
El neo patrimonialismo define tres grandes grupos de relaciones; 1) lógicas, 2) esenciales, 3) dimensionales y 4) ambientales; en este sentido, estos cuatro relacionamientos estarán dados en sus tres facetas o logos de la tesis, para garantizar relaciones de eficacia, tanto para el "ser contable"; como para el registro contable; y para la sostenibilidad o eficacia social, definida bajo una función de homomorfismo, entre la eficacia personal, la eficacia empresarial y la eficacia social, donde medie un ciber-registro contable íntegro que garantice el logro de los ODS.

\section{Desarrollo Teórico, Materiales y Métodos}

\section{Las corrientes filosóficas}

La naturaleza cuantitativa o medible de las variables de transparencia y eficacia empresarial y profesional, son producto del carácter positivista de la disciplina y podrá ser abordado para su análisis, a través de la estadística descriptiva; sin embargo, para el diseño y comprobación de los registros contables en cumplimiento de los ODS, se requerirá de un enfoque constructivista de carácter alternativo, participativo y colaborativo que apropie instrumentos integradores de múltiples disciplinas, múltiples dimensiones y múltiples saberes, logrando un apoyo irrestricto de los gobernantes, los reguladores, los académicos y los empresarios, para establecer a la contabilidad como garante de una ejecución presupuestal sin corrupción de ningún tipo: ni personal ni profesional; ni dentro, ni fuera de las organizaciones. Empresas y seres contables cada vez más eficientes para imponer estándares sociales con mayores oportunidades de felicidad. Es ésta, la idea principal del neo patrimonialismo con Lopes de Sá. 
El patrimonialismo, tiene gran acogida y aplicación en Brasil, en las Américas, en parte de Italia, Francia, Portugal, Argentina; en resumen, encontró aceptación internacional (Lopes de Sá, 2000).

La toma de postura o enfoque epistemológico para el desarrollo de la tesis, se apoya tanto en la corriente organizacional como en la patrimonialista, que permiten mayor profundidad y, han perdurado en la consagración científica de la contabilidad moderna del siglo XX.

Los principales cuestionamientos del positivismo frente al constructivismo social que requiere una ciencia del Bien Común, como lo es la contabilidad, y que se pretenden con la tesis, es que no es posible llegar a unos postulados de total completitud para garantizar el bien común; sin embargo, lo que se pretende no es llegar al absolutismo del registro contable; sino, al absolutismo en la aplicación de las fórmulas de eficacia, dentro y fuera de las organizaciones, por y para las células sociales en todas sus dimensiones y gradaciones contables.

Lopes de Sá, establece la aplicabilidad de los postulados biológicos de la célula, para explicar el fenómeno de la eficacia social, que nace de la eficacia de la ética y de la técnica emancipadora en cada comprobante contable, para demostrar la eficacia social.

El axioma principal de Lopes de Sá (1992), reza:

"Cuando la suma de la eficácia de todos los patrimônios implicar ne la suma da eficácia de todas las células sociales, en regimen de harmônica interación, esto implicará, logicamente, ne la eficácia social, equivalendo a la cancelación de las necesidades materiales de la humanidad" (1992:264). Nos brinda aquí el neo patrimonialismo grandes acercamientos al planteamiento inicial de la tesis, que permiten analogias importantes para las tres variables objeto de estudio en la propuesta: 1) El ser contable; 2) El Registro Contable y 3) La eficacia social: 


\section{Primer Logo}

El "ser" contable, representado por Lopes de Sá (1992), luego de hacer una recensión de la simbología del caduceo de Mercurio en la mitología clásica, basados en tres símbolos ancestrales de la profesión contable en Brasil, a saber: el caduceo de Mercurio, el anillo del contador con Rubelita o Turmalina Rosa y San Mateo como patrono de la profesión (CRCSC, 2017:12), resume en seis puntos las implicaciones que tiene la simbología para el ejercicio ético de la práctica contable:

1. La misión del contador es sagrada, como guardián de la riqueza que tiene como objetivo satisfacer las necesidades humanas de las células sociales en sus más altos ideales -como la que Júpiter le confirió a Mercurio-.

2. El contador asume el papel de protector del patrimonio de la organización con su saber prudencial de la contabilidad, ofreciendo las condiciones para la eficacia social de la riqueza -por analogía con el arte de prever, atributo de Mercurio, quien exhortaba al silencio para reflexionar la mejor manera de interpretar la periferia fenoménica-.

3. El contador no se obnubila por las apariencias; permanece casi en el anonimato, aunque tiene conocimiento global de la organización para lograr mejor su cometido -como lo hacía Mercurio-.

4. El contador tiene el control de la gestión del patrimonio, desde un punto de vista contable, al igual que Mercurio, cuando se ponía su casco para volverse invisible, a fin de controlar las acciones de los hombres y mantenerse en secreto, lo que hizo ocultándose materialmente.

5. El contador pone a disposición de la sociedad todo su leal entender del saber contable, ejerciendo la profesión con sigilo y prudencia-como lo sugiere la mitologia de Mercurio, quien con su vara con las serpientes 
enrolladas demostraba su poder para subir al cielo y bajar a la tierra, con el propósito de reivindicar las fuerzas de las cosas superiores e inferiores.

6. El contador permanece siempre ocupado, para ejercer la profesión de manera competente y competitiva, frente a la velocidad con que ocurren las prácticas en la vida de las empresas e instituciones -como lo hizo el diligente y ocupadísimo Mercurio como mensajero de los dioses-.

Para una mejor comprensión, se lee su poema, sin fecha, siguiendo en lo posible la fuerza de las palabras de su lenguaje hermético, para entender al ser contable:

¿Cómo ser...? Ser como...

¿Cómo ser humano? Sé como la tierra: fecundo en cualidades, sólido de actos; parte inequivocamente autónoma de un sistema, e iluminada por una jerarquía de valores.

¿Cómo ser gregario? Sé como el agua: toma la forma de tu a mbiente, contornea los obstáculos dando los rodeos precisos más sin perder de vista la meta del bien.

¿Cómo ser cósmico? Sé como el aire: está presente en todos los espacios; dando vida a cuanto toque, alimenta de amor a la vida.

¿Cómo ser eterno? Sé como el fuego: da tu luz sin reparos; tu calor mate el frio; incéndiate de vida y de conocimiento $y$, sean las cenizas de tu combustión abono de tu suelo.

Entonces, cumplida esta etapa, acecha libre, sideral, extra galáctico, en forma de energía, el mundo de lo compuesto en pos de constelaciones y soles inéditos. He aquí la eternidad, sucesión de renacimientos y muertes, cada una de las cuales no es más que un experimento de integraciones futuras.

Antônio Lopes de Sá (sine data) [Traducción de Roberto Pinzón, 2020] 
La respuesta al porqué este autor se considera un referente importante para la tesis, está dada en la empatía frente a esta postura semántica, ética y conceptual, al definir al ser contable, como el primer responsable de la eficacia social y empresarial; el bien común.

\section{Segundo Logo}

Consiste en la normatividad del quehacer positivista y normativo de la contabilidad, que ha de ser intervenido por la identidad ética y moral del contador público.

Encontramos en el neo patrimonialismo, la explicación de la lógica entre el "ser" y el "hacer", que dice:

Las relaciones de los conceptos y proposiciones entre sí son de naturaleza lógica, y el quehacer del pensamiento lógico se limita estrictamente a establecer la conexión de conceptosy proposiciones entre sí, según reglas fijas, sobre las cuales versa la lógica. Los conceptos y proposiciones solo cobran "sentido" o "contenido" a través de su relación con experiencias de los sentidos (Einstein, 2016:23).

La ética y la identidad del "ser en su hacer" contable, se materializa en un registro ordenado e íntegro de comprobación, para dar fe pública, en pro del bien común y del cumplimiento de los ODS.

De acuerdo con el neo patrimonialismo, la contabilidad contribuye a las formas de administrar la riqueza correctamente, sirviéndose del control para regular el comportamiento de los fenómenos patrimoniales de una célula social. Sin una doctrina o una forma de pensar en la búsqueda de la verdad, la contabilidad se vuelve una práctica vana, sin razonamiento, o una actividad que puede servir a la mentira, al fraude y a la mistificación de representaciones patrimoniales, en perjuicio de su impacto social. 
Una razón más para entrever en su estructura de conocimiento contable, un argumento para la definición de los registros contables en su función de representar cualitativa y cuantitativamente, una realidad que garantice la eficacia tanto personal y profesional, como empresarial y social, en el logro del bien común y de la sostenibilidad de la vida en el planeta.

\section{Tercer Logo}

La eficacia empresarial en todas las dimensiones económicas, sociales y ambientales, garantiza un crecimiento y un mejoramiento continuo, sostenible socialmente, que aparece representado por el neo patrimonialismo con la teoría de las funciones patrimoniales, donde el motivo primordial que llevó a Lopes de Sá a elaborar su teoría fue la búsqueda de la eficacia de las células sociales, la cual se da al realizar la capacidad de los medios en coordinación con los fines supremos de la sociedad; siendo para éste caso los ODS.

Asimismo, en su teoría de las funciones patrimoniales, representa la efectividad de la célula social, como una función de satisfacción de necesidades bajo tres relaciones lógicas de re presentación contable: una primera que versa sobre la esencia del hecho patrimonial, su potencialidad funcional, su funcionalidad real y la integración al funcionamiento total del proceso evolutivo de la organización; una segunda lógica, en relación dimensional o teleológica que asegure el análisis de seis dimensiones: 1. La causa u origen, 2. El efecto o la consecuencia, 3. El tiempo, 4. El espacio, 5. La cualidad y 6. La cantidad.

Y una tercera lógica ambiental o de contexto, tanto interno como externo, que han de guiar las funciones administrativas y psíquicas al interior de la organización, y las funciones económicas, sociales, 
políticas, legales, ecológicas, científicas y tecnológicas, de carácter externo a la organización.

En un primer acercamiento, se podría decir que, la variable de eficacia en el registro contable, encuentra en esta trilogía, una función de homomorfismo entre la intencionalidad de la empresa y la del contador, al efectuar el registro o el comprobante contable, vs, el resultado de los indicadores de eficacia empresarial, en función de dar cumplimientoa los ODS.

De manera que, aquí nace una pregunta, ¿Cómo puede el registro contable aplicar técnicas emancipatorias para dar cumplimiento a los ODS?

Para Lopes de Sá (1992) en su Teoría General del Conocimiento Contable' que describe a través del método inductivo (positivista), que le concede al patrimonio la facultad de expresividad y representación universal de los fenómenos observables (dinámica de la organización), y partir de categorias como esencia, dimensión y ambiente, intenta definir el principio de existencia, de la causa primera que motiva el surgimiento del patrimonioy su latencia, en el sentido de movimiento en favor de la acumulación de la riqueza.

Su teoría parte de inferir en la causación del patrimonio: el propósito humano de realización de sus necesidades. Todo se inicia allí, y a partir de las necesidades (n) se buscan los medios (m) para satisfacerlas, en dirección de sus finalidades (Fi). Esta es la estructura central de su teoría, de ella derivan desdoblamientos que permiten detectar la dinámica de la organización por medio de la cual la célula social (organización) propende a la eficacia plena (Ea).

La empatía de la tesis para con la personalidad de Lopes de Sá, está dada gracias a sus charlas grabadas y a sus maravillosas escrituras que 
nos permiten percibir su gran integridad ética, cultural y social al hablar, su autenticidad al razonar y su veracidad en la toma de sus posturas filosóficas de base científica, dando evidencia real, del poder de la contabilidad para lograr el bien social.

La sencillez de sus formas de enseñar, su mirada perspicaz con un entonado acento brasileño, amoroso y sensual; nos habla en italoportugues, para entregarnos en cada palabra un corazón amplio y una mente fantástica que refleja imágenes mágicas, confabuladas para conectarnos con la función contable; para hacernos entender, que la naturaleza y el objeto de la ciencia contable, tiene como principal objetivo, asegurar el bien social.

Lopes de Sá, ha cautivado territorios y corazones contables que están despertando en latinoamerica, y que se encaminan hacia una nueva era filosófica y científica, en busca de su liberación y consolidación como pueblos de paz. Su sapiencia contablele ha permitido desarrollar grandes obras sobre la teoría contable; así como también, permitió la escritura y la publicación del libro en Colombia; 'Lopes de Sá, El filósofo de la contabilidad'.

Este autor con su teoría de las funciones sistémicas del patrimonio, trasluce un poco la cuestión de la esencia contable, al definirlo como la riqueza que se obtiene de la eficacia organizacional, en analogía a la célula en el organismo bajo el postulado de que, sólo podrá generarse una riqueza real, cuando la totalidad de las células que conforman el organismo, logran satisfacer de forma eficiente, sus necesidades sistémicas.

Bajo esta teoria, la tesis centra su objetivo en el registro contable patrimonial para garantizar la sostenibilidad de dicha riqueza, dando cumplimiento a los ODS; para lo cual habrá que identificar los elementos 
patrimoniales que definen las variables del registro contable, para su preservación.

En la dimensión patrimonial, emergen patrimonios ecológicos que expresan el derecho a un ambiente sano y la cultura organizacional como columna vertebral del capital simbólico, que logra, por el establecimiento de sistemas de valores compartidos, no sobre la voluntad de algún agente en particular, sino sobre el concepto de interés público, que pretende determinar las virtudes orientadoras de la acción organizacional. Derivados de ellos los patrimonios económicos con sus elementos de capital fijo y variable, no necesariamente en la perspectiva de generación de ganancia sino en el de la conservación del patrimonio (Franco, 2012a:159-160).

Esta visión patrimonial es totalmente opuesta a la lógica internacional emanada de IASB e IFAC, donde el patrimonio es la participación residual en los activos netos de una entidad, lo cual es una visión miope de la perenne concepción y amplitud de lo patrimonial. La tesis presenta una visión heterodoxa, alternativa o emergente, que bien puede estar siendo apoyada por la teoría de las funciones patrimoniales del doctor Lopes de Sá.

Lopes de Sá (2010b) se opone a la inmersión de la contabilidad en el campo de la economía, aduciendo que sus conceptos no están moldeados por el mercado de capitales; tal es el caso del valor razonable, de modo que es preciso realizar nuevos estudios más contundentes que propendan a restablecer la autonomía de la ciencia contable.

García Casella et al. (2001), en el marco de su Teoría general de la contabilidad, argumentan que la contabilidad no se trata únicamente de fenómenos económicos, ni tan poco una parte de la economía ni mucho menos la ciencia del control económico (2001:14). 
La lógica del lenguaje contable de Lopes de Sá nos dice que los principios fundamentales de la actividad científica no surgen del libre consenso de las reglas discursivas del nominalismo, pues la lógica de la investigación científica se opone a la idea de que la ciencia sea una creación artificial del sabio.

Bajo esta postura, el enfoque de estudio del fonómeno a abordar en la tesis, estará centrado en el diseño de un registro integrado, en la que se contrasten métodos de medición para destruir paradigmas y descubrir paradojas que fomenten la sed científica en el acervo dialógico, dialéctico y discursivo de los contables; desde el "ser" para el "hacer", fundamentando a la contabilidad como una ciencia universal del Bien Común.

Esta labor contable, ha de representar una realidad que pueda ser vista y atendida en todas sus dimensiones técnicas, científicas, filosóficas, epistemológicas, teleológicas, axiológicas y ontológicas, por parte del cuerpo normativo y académico disciplinar, como evidencia o prueba, para garantizar el cumplimiento de la totalidad de los preceptos de la disciplina y la transdisciplina, que han de ser aplicados para dar fe pública de la sostenibilidad y de la sustentabilidad de las organizaciones en un planeta sano, libre de corrupción.

\section{La técnica del registro contable}

¿De qué debemos emanciparnos?

La mirada crítica de la epistemología a la contabilidad representada en obras como la de Sousa Santos, que muestra un camino para la emancipación del conocimiento científico para recuperar conocimientos olvidados, tal vez, que nos lleven en una aventura fascinante, a danzar entre regulación y emancipación, entre la apropiación y la violencia, para 
desplazar la razón indolente de la tecnología, he ir recuperando el sentido común, para una transformación real del ser humano, a través de la contabilidad del bien común.

La contabilidad debe tener una voz que se alce de forma libre de los discursos dominantes, para explorar y explicar las posiciones de utilidad e integridad de una técnica contable que, de fe pública del bien común, bajo una ecología de saberes que le permita superar el desperdicio de la experiencia y del conocimiento en la ciencia moderna. El paradigma emancipatorio permite al fenómeno humano emerger y ser investigado.

En la actualidad se está logrando un cambio, pasando de una contabilidad orientada por la irracionalidad del desarrollo tecnológico, del dominio y del poder, hacia una contabilidad más humana y centrada en el bien común, y para ello es necesario empezar a escudriñar sobre las estructuras del sistema contable, que puedan estar beneficiando la hegemonía.

De acuerdo con el profesor Franco (2016), cuando se refiere a la representación contable como proceso que incorpora estimaciones subjetivas sobre los recursos representados por las cuentas reales que permiten orientar las representaciones contables hacia los intereses de los agentes sociales hegemónicos en dos direcciones. La primera, ocultar el origen de la creación de riqueza por el trabajo incorporado en los procesos de producción, creando la ilusión de transparencia (Bourdieu, Chamboredon \& Passeron, 1981) de que ésta es producto de la habilidad empresarial en los procesos de venta.

La segunda dirección, para privilegiar a los inversionistas estratégicos frente a los inversionistas rentistas, al minimizar el cálculo de ganancias a distribuir por la estimación acotada de gastos de producción y transacción a través de depreciaciones, amortizaciones y agotamientos, 
dando origen a reservas secretas, patrimonios no representados (Franco, 2016:277).

La contabilidad se ha prestado como instrumento individualizador y privativo de derecho social, marcada por el carácter transitorio y volátil de sus relaciones estatales, sin responsabilidad hacia el bien común; se reduce al vínculo sin rostro ético que ofrece el sistema contable en la esfera financiera, de una hiperrealidad económica, que no le permite generar información fiel, verídica y confiable de la real situación del balance humano.

\section{Resultados}

En la ponencia titulada "Etnografia epistemológica para la emancipación contable", escrita por el autor y aprobada para su presentación ante la asamblea de la XXXII Conferencia Académica Permanente de Investigación Contable, llevada a cabo de forma on-line, durante los dias 17 al 19 de noviembre del 2021, organizada por la Universidad Austral de Chile, dio cabida a la fundamentación y la legitimación de los saberes emancipadores de la contabilidad, que han de guiar la práctica disciplinar del sujeto contable, asegurando las experiencias y las razones para el cumplimiento de los preceptos de autenticidad, rectitud y veracidad, liberándose de los paradigmas racionalistas y lógicos que ha desarrollado la modernidad en el S.XX.

Durante el desarrollo de la tesis doctoral en el posgrado de ciencias contables de la ULA, se establece un recorrido filosófico, metodológico, ontológico y epistemológico, del cual fue publicado un artículo en la revista Científica Arbitrada de la Fundación Mente Clara, titulado: ' $E l$ interés emancipador de la ciencia contable. Un recorrido epistemológico', en donde se obtuvieron los primeros contenidos epistemológicos para la 
fundamentación epistemológica de la contabilidad como ciencia universal del BC; sin embargo, el aprendizaje metodológico toma un rumbo diametralmente opuesto cuando se llega a la etnografia.

La hermenéutica y la fenomenología permiten visualizar el horizonte de percepción ontológica y gnoseológica de la contabilidad; sin embargo, la etnografia, permite la significación vívida de los fenómenos entre investigadores, y genera una experiencia en la que se descubren y nacen nuevos sentidos y nuevas sensaciones para la comunicación y el crecimiento entre humanos.

Estas nuevas formas de pensarel problema, de entender al sujeto y de sentir lo observado por el otro a través del objeto de investigación, le adicionan al proceso investigativo, nuevos métodos e instrumentos emancipadores contables, para garantizar un registro integro del bien común, en cada transacción económica.

La etnografia ilumina cualquier atisbo de encadenamiento, entendido este como la falta de sentido de toda acción de la técnica contable que no cumpla con la ecuación patrimonial del Bien Común. El contador, etnográficamente, encuentra su papel en la sociedad, a través del registro contable; sólo allí, y desde allí, puede dar fe pública del interés público y garantizar una efectiva estabilidad empresarial que perdure en el tiempo.

Es sólo en ese momento del registro contable, donde el poder de la técnica podrá garantizar el bien común; puesto que exige un cambio de paradigmas fenomenológicos que sólo pueden ser abordados a través de una radiografía detallada, dialógica, histórica y académica de la función patrimonial, en cumplimiento del interés público, asegurando la sostenibilidad de la vida en un planeta sano.

El acercamiento etnográfico al objeto de estudio, permite también una aproximación a los métodos, los procedimientos y los instrumentos de la 
técnica; así como a las concepciones y las prácticas contables, para asegurar el bien común.

¿Cómo lograr una lógica metódica para garantizar registros contables que den cumplimento a los ODS?

Uno de los elementos principales que ha de ser entendido y etnografiado, es el compendio de saberes contables en todas sus formas discursivas, dialógicas y teóricas, que puedan enriquecer el acervo disciplinar para fundamentar a la contabilidad como ciencia universal del bien común. De acuerdo con Lopes de Sá (2010b), a los discursos argumentativos subyacen ciertas creencias de diverso tipo racional, irracional, ideológico, entre otras modalidades discursivas, que no necesariamente puedan estar alineadas al bien común. En este sentido, es necesario que la proposición de los hechos, represente la realidad desde múltiples relaciones espacio-temporales que garanticen la razonabilidad del bien común, en cada registro contable.

El método etnográfico permite leer, escribir, escuchar, sentir y comprender al otro, bajo un común entendimiento, comprensión y acuerdo de los involucrados en lo social y lo ambiental del sistema económico, como stackeholders de la organización en un horizonte que posibilite dimensionar sus impactos. El contador público con su rúbrica imprime en cada acto o hecho económico, como ser contable, como ser profesional y como ser empresarial, dentro y fuera de la organización, su huella de forma indeleble para garantizar la transparencia, y el crecimiento en igualdad de condiciones para hacer cumplir los ODS.

Al profesor Lopes de Sá se le identifica en su filosofia, por tener una visión palpable de las consecuencias que ha traído la ciencia positivista durante el último siglo, y que tiene a la ciencia contable como algo peyorativo, sin sustento cientifico, cumpliendo una labor servil de muy 
bajo rendimiento cultural, ético, social, ambiental o económico, de irracionales acciones, que se registran en el sistema contable, sin que se apliquen o medien técnicas especializadas en los ODS, lo que ha permitido esta hecatombe de corrupción lo cual, no le permite definirse como ciencia. Por ello, Lopes de Sá, considera necesario una teoría de la regulación contable que propenda a la protección del interés público y a la eficacia social en la medición del desempeño económico, social y ambiental de las organizaciones.

Es aquí, donde aparece como requisito básico e indispensable, la aplicación de todas y cada una de las teorias, métodos y modelos de medición tridimensional y contamétrico, para garantizar la eficacia social a partir de la eficacia empresarial, dando cumplimiento a los ODS.

El pensamiento disociado, separatista y práctico de la regulación contable, ha desviado el verdadero sentido del "'Interés Público", frente al bien común; lo cual, no le permite cumplir con su función de asegurar el cumplimiento de las fórmulas patrimoniales de eficacia, dentro y fuera de las organizaciones.

Desde una perspectiva profesional, Spencer (2020) señala que "me he encontrado desafiado cuando pienso en el interés público y el bien común. Se sienten como compañeros de cama incómodos" (2020:1). Totalmente opuestos, bajo la falacia de intereses interpuestos abusivamente, como un designio y no, con una postura autónoma que busca la realización de un fin social y empresarialmente eficaz.

La eficacia, aparece entonces como el termómetro del bienestar profesional, social y empresarial, mediado por un registro contable que asegure el cumplimiento de los preceptos, bajo la ética, garantizando la eficacia total para la humanidad. 
Este movimiento que se genera al incentivar el poder emancipador que posee la técnica contable, bajo preceptos de eficacia, le permite hacer cumplir la eficiencia y la efectividad de los negocios, de las naciones y de los seres contables, que, a manera de avatar, validan de forma paralela las realidades para que estén alineadas en el logro de los ODS. Un registro integro, que garantice una postura ética tanto del profesional, como de las organizaciones.

El marco de las Normas Internacionales de Información Financiera NIIF, define el interés público como distinto de los intereses privados del capital. Con esta perspectiva, actuar en interés público puede ser visto como una externalidad, incompatible con una lógica comercial.

Bajo esta premisa, el bien común no podrá ser adoptado ni aceptado por la organización, sin que medie un cuadro de mando, alimentado por registros contables exacerbados en su sentido hacia el bien común, y representados por la medición del impacto social, ambientaly de negocio, en cada una de las transacciones o hechos económicos de la organización; que a manera de célula individual, colectiva y orgánica han de garantizar, a través de un registro ético y cibernéticamente seguro, la eficacia del ser y de la sociedad.

Se han de integrar todos los mecanismos informáticos para asegurar el manejo eficiente de los recursos, las intencionalidades y los discursos, para que, de forma eficiente y ética, se realice el registro de cada una de las transacciones, con la debida autorización, validación y ejecución bajo preceptos de calidad, mejoramiento continuo e interdisciplinaridad.

La perspectiva etnográfica sobre el bien común, reconoce que la propia empresa forma parte del conjunto; así, igualmente no es posible separar el ser de su hacer eficaz en el negocio, las organizaciones y la sociedad. La integración o conjunción en el actuar con los demás puede alcanzar 
objetivos comunes que estén alineados con los intereses privados y públicos. Este encuadre del bien común es un concepto fundacional útil con el que recalibrar nuestra comprensión del interés público, lo que podría permitirnos reconsiderar, cómo la contabilidad puede convertirse en un activo facilitador de las respuestas a las crisis mundiales.

Esto puede implicar reconocer y mantener una tensión creativa entre el individuo y lo comunal, más bien como se mantienen las lógicas comerciales y profesionales en el campo de la auditoria, como se describe en Gendron (2002)".

¿Cómo podrían los institutos internacionales, emisores de estándares contables, atender el interés público?

Es evidente que los individuos necesitamos poder satisfacer intereses individuales. De igual manera, en muchas ocasiones, como en torno a las bolsas en los mercados de valores, muchos individuos tienen unos mismos intereses. No se trata de que la contabilidad satisfaga solamente intereses de uno o de muchos. Se trata de que la contabilidad también debe procurar el bien de todos, que generalmente es diferente al bien de muchos" (Gómez, 2020).

Las politicas y el poder que ejercen la IASB y el IFAC, no están atendiendo ni lo racional ni lo epistemológico, en la ejecución de las políticas, normas o estándares; a pesar de que el código de ética establece las pautas, los requisitos de forma y de fondo para el reconocimiento, la medición, la presentación y la revelación de las transacciones, no apuntan a la consecución de los ODS.

"Podemos enredarnos en las posibilidades de significado que acompañan a las palabras; podemos construir teorias a partir de ciertas definiciones. Esto es parte de la riqueza de los idiomas. Lo que no 
debemos es dar la espalda a la raza humana y a la casa común" (Gómez. 2020).

Etnográficamente, se hace necesario esclarecer las intencionalidades de los grupos de interés que se ven afectados por una fórmula contable universal del bien común, dando cumplimiento a los ODS.

El proyecto de investigación para la comprobación de esta tesis en su objetivo de fundamentar a la contabilidad como ciencia universal del bien común, se apoya en Lópes de Sá con el concepto de patrimonio organizacional como una representación socioeconómica micro - macro de la interacción interna y externa de las células sociales en equilibrio, dirigida a la eficacia social.

De la suma de las eficacias sociales viene la "prosperidad social", el neo patrimonialismo contable se basa en la filosofia del respeto del Estado y de todos los intereses del patrimonio individualy sus relaciones, es decir, busca la armonía y la conciliación. (Lopes de Sá, 2012b:186)

Equilibrio que ha de asegurarse de manera que el comprobante contable registre cada una de las variables de medición que evidencien la eficacia en todas las dimensiones dentro y fuera de la organización, que conforman el patrimonio social.

El registro y control del patrimonio de la humanidad está a cargo de la contabilidad en su función de dar fe pública de la preservación y control de activos, que están constituidos por los recursos públicos, como patrimonio de la humanidad y son considerados vitales para la viabilidad de la vida misma; por tanto, la contabilidad tiene la responsabilidad de controlar e informar sobre la representación del bien común para garantizar la vida en el planeta. 
La riqueza patrimonial entendida como la satisfacción plena de necesidades que nacen de propender por los fines supremos en el Bien Común, y no de los individuales o de falsas colectividades.

La tesis doctoral deberá entonces aplicar métodos y metodologias afines a la etnografia para elaborar el mapa cartográfico de las concepciones epistemológicas, ontológicas y axiológicas del comprobante contable a través del laboratorio y el consultorio contable, en donde se pondrán a prueba para dejar testimonio de los resultados de las vivencias y las experiencias históricamente situadas en entornos disciplinares para garantizar el cumplimiento de los ODS

El método etnográfico ha de diseñar herramientas e instrumentos para validar los preceptos, postulados y teorías de la contabilidad como ciencia universal del Bien Común, en donde, estudiantes en terminación académica, pongan a prueba los indicadores del Bien Común, abordando la totalidad de los objetivos de la contabilidad e integrando las funciones del patrimonio para asegurar el logro de los ODS.

La contextualización dialógica en la trilogía de la tesis, implica una dialéctica específica en cada una de las labores del contador al momento de plasmar su rúbrica bajo la autoridad como supervisor de las transacciones para garantizar la eficacia celular, organizacional y social, ostentando una postura ética y científica que le posibilite la proyección y, validación de los preceptos del Bien Común, dando cumplimiento a los ODS.

La contabilidad conforma un cuerpo teórico emancipador, en función del registro contable para atender la totalidad de las dimensiones celulares, organizacionales y sociales, de las que habla Lópes de Sá. Así mismo, deberá analizar los riesgos generales del entorno financiero, ambiental, político, social y cultural entre otros, garantizando así un 
registro íntegro, integral y definitivo para la sostenibilidad de la vida en el planeta.

La heteroglosia entre el ser como célula social, la organización y la sociedad, ha de centrarse en la formulación de estrategias para la eficacia y desde la eficacia, en todos y cada uno de los registros contables, que, contando con tecnología de punta, el block chain, y los sistemas más avanzados, logren asegurar el cumplimiento de los ODS y garantizar el BC.

La manifestación de los pensamientos y concepciones del contador público han de estar alineados por la eficacia celular, organizacional y social que han de generarse al momento del registro contable, y que representan la teoría de funciones patrimoniales de Lópes de Sá: liquidez, rentabilidad, perdurabilidad, estabilidad, invulnerabilidad, productividad, elasticidad y efectividad social, necesarios para lograr los ODS y cumplir con los preceptos del BC.

\section{El ser y el hacer eficaz}

El contexto fenomenológico para la definición de un registro contable unificado, íntegro y automatizado para el cumplimiento de los ODS, requerirá de una sensibilización cultural, histórica y tecnológica, en donde se pueda demostrar de forma hipotético deductiva, la implicación que logra un registro ético, para evitar la ineficacia social que tiene al planeta plagado de males ambientales, sociales y económicos, sin precedentes.

El proyecto debe establecer la forma de demostrar que, a través de un registro íntegro, se logra una intervención precisa, mediaday estratégica, que permite evitar, detectar o corregir cualquier riesgo de error o fraude que afecte la eficacia social. Todas los normas regulatorias, propositivas 
y definitorias de la teoría contable, se deben hacer cumplir en el registro contable; la firma del ser contable será la garantía del bien común. Allí actúa un ser que se representa y representa la realidad para garantizar la eficacia social.

Nace un nuevo interrogante, ¿Cómo lograr concatenar variables de sostenibilidad en cada una de las transacciones económicas?

La respuesta la tiene Lópes de Sá, cuando nos habla de los axiomas de las lógicas de la célula social en la práctica económica y contable que hacen que el contador deba objetivar los contenidos de la norma internacional, bajo la lógica del bien común para lograr integrar al valor monetario, el valor moral y ético, que asegure el logro de los ODS.

Las relaciones axiomáticas de la lógica entre conceptos y preposiciones de la tesis, se pueden argumentar con base en los axiomas del neopatrimonialismo de Lópes de Sá, en su sistema de funciones patrimoniales.

Los cinco grandes axiomas de la contabilidad de Lópes de Sá, establecen que: 1) El patrimonio se transforma, conforme mutan los organismos y las células sociales; 2) La efectividad consiste en la satisfacción de las necesidades, la efectividad contable consiste en lograr la satisfacción total y sistémica de las necesidades básicas de las células y los organismos sociales; 3) Existen tres elementos básicos en el relacionamiento de las células y organismos sociales, la esencia, la dimensión y el contexto, por tanto, la contabilidad debe reflejar la realidad patrimonial, bajo estos tres elementos; 4) De la relevancia, autonomía e independencia de los sistemas, depende la efectividad social, por ello la contabilidad debe dar cuenta de los resultados, la estabilidad, la productividad, la invulnerabilidad y la elasticidad, que permea las esferas económicas y contables dentro y fuera de la organización. 
En sus sistemas de funciones patrimoniales, Lópes de Sá dice que, los axiomas que sirvieron de fundamento lógico a su teoría se inspiraron en esta afirmación de Albert Einstein que escribiera en sus Notas autobiográficas:

Las relaciones de los conceptos y proposiciones entre sí son de naturaleza lógica, y el quehacer del pensamiento lógico se limita estrictamente a establecer la conexión de conceptosy proposiciones entre sí, según reglas fijas, sobre las cuales versa la lógica. Los conceptos y proposiciones solo cobran "sentido" o "contenido" a través de su relación con experiencias de los sentidos (Einstein, 1984:23).

La función de la contabilidad de dar fe pública bajo los preceptos del bien común, del interés público y de la sostenibilidad de las organizaciones, ha de reflejar una realidad latente, sin nominalismos o prejuicios estáticos que no garantizan la razonabilidad de las cifras de nuestra cruda y atroz realidad en permanente crisis. En palabras de Demócrito de Abdera, "Es una ardua tarea penetrar en las cualidades reales de cada cosa"; será esta, la labor del ser contable en cada registro, en cada hecho económico, en el que se perpetuará su ser.

Esta labor del quehacer contable, que se requiere en cada uno de los comprobantes contables para la cuantificación y la aplicación de técnicas y teorias contamétricas de lo económico, lo financiero, lo social y lo ambiental, en cada hecho o transacción económica que opere en la organización y de la cual quedará firmado con carácter comprobatorio, la real eficacia del ser en su hacer contable, o transacción económica, firmada por el contador público, como dador de confianza a través de la fe pública, del bien común. 
¿Cómo lograr esta visión tridimensional y contamétrica en cada uno de los hechos económicos de las organizaciones para asegurar la eficacia social?

Para responder esta pregunta Lópes de Sá propone ocho índices básicos para medir el desempeño económico, ambiental y social en todo tipo de organizaciones que se axiomatizan en la génesis del fenómeno patrimonial. En donde el ser contable ha de percibir la realidad, bajo la intencionalidad de hacer cumplir el bien común. Dependerá entonces, de la voluntad de cada ser contable, tanto la idealización, como la posterior materialización de la eficacia, evidenciada en resultados palpables de riqueza y bienestar para la totalidad de los pobladores de la tierra. Esta voluntad personal, política y social que se requiere, en el diseño y programación de un registro integrado y cibernéticamente seguro, estará representada por la totalidad de los contadores activos al momento de la muestra, y la evidencia del cumplimiento de los ODS, estará inserta en los métodos e instrumentos para su manejo. El modelo, la concentración de voluntades contables, en representación de las naciones en busca de paz.

Los modelos de eficacia, su ideación y su materialización dependerán de lo humano, que según Lópes de Sá (2005), se establece por la voluntad que genera la percepción de la necesidad y su intencionalidad eficaz para satisfacer el medio patrimonial, materializado en el bien común. Así las cosas, esta ideación y esta materialización, estaría dada en un registro integro, y holístico, de cada uno de los hechos y transacciones económicas, sociales y ambientales, que den cuenta del bien común. El ser contable debe percibir la realidad, objetivando los nominalismos, para entrar a describir de forma científica y etnográfica las afectaciones y variaciones que se produzcan en la riqueza patrimonial y en la equidad económica, social y ambiental. 
El bien común, estará entonces entre la organización y los stackeholders, ¿o entre la de todos?

El doctor García Casella considera que la contabilidad debe conjugar cuatro tipos de objetividad. Primero, la legal o jurídica, para el cumplimiento de regulaciones y normalizaciones derivadas de regulaciones públicas o profesionales. Segundo, la objetividad científica, que busca criterios de fundamentación teórico-conceptual, ausente de juicios de valor internos o externos a las intencionalidades de grupos de interés particulares y que busca una única verdad. Tercero, la objetividad teleológica o instrumental que aplica técnicas, procedimientos e instrumentos que persiguen la confección de información dirigida a cumplir propósitos específicos. Por último, la constatación o validación socioambiental, que pretende determinar el grado de aporte de la contabilidad a los procesos de sostenibilidad de los recursos naturales y a la cohesión social.

El ser contable, ha de atender estos cuatro tipos de objetividad en el comprobante contable, dando evidencia de su razón ética, profesional y científica para el logro de los ODS.

García-Casella (2001a, pp. 121), indica que los registros contables, al ser amplios y completos, hacen que la contabilidad se considere ciencia. Ciencia que, según las leyes aplicables a los modelos bajo la teoría contable, deben atender: 1) La generalización y la abstracción teórica se exteriorizan por medio de distintos tipos de modelos contables que pretenden representar distintas realidades sociales en las organizaciones. 2) Los modelos se estructuran mediante la definición de elementos objetivos y de realidades sociales que pretenden exteriorizar distintas situaciones en función de los objetivos planteados por distintos 
usuarios de la información contable. Y 3) No hay un único modelo capaz de exteriorizar la compleja realidad social de las organizaciones.

Bajo estas tres leyes, el comprobante contable ha de atender desafiantes transformaciones políticas, sociales, económicas, ambientales y tecnológicas, que afectan la información contable en su función de dar fe pública del bien común.

El ser contable, encuentra todo un desafio, al tener que comprender, adaptar y aplicar modelos contables para la cuantificación monetaria, exclusivos de la valoración patrimonial, y que se puedan definir a partir de elementos que no necesariamente son susceptibles de cuantificación monetaria. En este encuadre valorativo, entre lo cuántico y lo cualitativo; aparece el registro contable, como el principal paradigma, en su función de eficacia, para asegurar como dice Tua Pereda (1983), un beneficio verdadero y la utilidad de la información en la toma de decisiones.

Este desafio puede afrontarse de manera positivista y, a la vez alternativa, pues el registro contable será aplicado para dar cumplimiento de los preceptos teóricos, que para el caso de la tesis, serán los del neo patrimonialismo con sus funciones sistémicas de efectividad tanto de las células como de los organismos sociales y culturales, a través de las estadísticas descriptivas; y, a través del método etnográfico se ha de lograr el encuadre teórico de la praxis ética y técnica que depende de las cualidades de la voluntad de cada una de las células para lograr la eficacia social en el logro de los ODS.

El ser contable con su firma en el registro contable, ha de demostrar tanto la eficacia personal, en tanto ha de comunicar sentimientos, pensamientos y concepciones claras frente al cumplimiento de los ODS, como la eficacia profesional, en tanto mide y evalúa el impacto del negocio en cumplimiento de la eficacia social. 
El registro se convierte en un espejo de doble cara, en el que se verá reflejado, tanto el ser, como el hacer, de un contador, que, a través de ese registro contable, deja su legado y su obra, en el bien común.

Aquí, el autor Lopes de Sá, nos muestra un camino posible, el de una conciencia contable que se abre hacia nuevos horizontes ontológicos alejándose del pensamiento clásico de una economía decadente, injusta e incompetente, y que ahora se empodera y emancipa, a través de una técnica contable íntegra, ética y cibernéticamente exacta, para lograr el cumplimiento de los ODS.

En la búsqueda de una fórmula patrimonialista del bien común, se establece un método inductivo deductivo, que relaciona bases de datos cibernéticamente seguras, a través del registro contabley bajo fidedignas condiciones de eficacia, medida sobre metas, planes y proyectos para cumplir con los ODS. Cada registro reflejará, tanto al ser como al hacer; medidos estos en términos de eficacia.

Las normas internacionales de educación contable, establecen las posturas éticas en las prácticas para evitar todo tipo de sesgo o subjetividad; y la imagen que queda, hace de cada ser contable, la imagen fiel de la eficacia organizacional y social como intencionalidad última de la contabilidad, bajo normas de ética, calidad, auditoríay aseguramiento, en cumplimiento de la lógica contable y de los estándares para el ser contable, para dar fe público del bien común.

La dialéctica del ser contable, no debe caer en la posición positivista del cumplimiento a ciegas o a espaldas de la realidad circundante, que se amalgama en los mecanismos de poder mediático, haciendo de las empresas, grandes hecatombes de corrupción. Se hace necesario que allí donde exista un registro contable, de todas y cada una de las transacciones económicas, financieras, y administrativas, se de evidencia 
de la eficaz y fiel representación del bien común, como célula social, asegurando la eficacia social.

La epifanía del ser contable se devela bajo el positivismo, como una imprecisión; ya que, considera lo cualitativo, como totalmente opuesto a lo cuántico, desconectando su estructura biológica, y sólo se conforma con bases estadístico descriptivas, e instrumentos métricos insuficientes, para identificar y valorar la voluntad de un ser contable que ha de desempeñarse eficazmente como célula social, para lograr la eficacia social de las organizaciones y de los pueblos.

Cuando la contabilidad logra demostrar las causas o fuerzas que ejercieron efecto en el movimiento del objeto estudiado, está ejerciendo ciencia y/o expresando verdades científicas, que seguirán siendo las mismas, con independencia al tiempo y al espacio. Dichas verdades, para el contador, serán aquellas que demuestren econométrica y contamétricamente el bien común, en el registro contable de cada transacción.

La contabilidad en su cientificidad, genera conocimiento al penetrar la esencia o la realidad más profunda del acontecimiento patrimonial para asegurar el bien común en todos y cada uno de los comprobantes contables en los que se registre dicha realidad. Por ello, la formación del ser contable como responsable en el desenvolvimiento científico del objeto de estudio de la contabilidad, debe solucionar cualquier intento por boicotear el bien común. Así mismo, y por su carácter de ciencia social, ha de resolver académica y profesionalmente lo que nos dice Cervantes que le sucedió a Don Quijote cuando salió al campo, rebosante de alegría por haber dado principio a su designio. De repente se embargó en las más graves reflexiones, [...] que por poco le hiciera dejar la comenzada empresa; y fue que le vino a la memoria que no era armado caballero y 
que, conforme a ley de caballería, ni podía ni debía tomar armas con ningún caballero, y puesto que lo fuera, había de llevar armas blancas, como novel caballero, sin empresa en el escudo, hasta que por su esfuerzo la ganase. (DQ, p. 206). Así mismo, el contador público a la hora de obtener su título profesional para cumplir con su designio de dar fe pública del bien común, ha de emprender la tarea de empuñar un arma blanca que representará y dibujará el grado de eficacia ética, según el resultado de su esfuerzo por cumplir los ODS, bajo las normas contables de ética, calidad, auditoría y aseguramiento, atestando y aumentando con su firma, una confianza pública en el bien común; todo evidenciado en cada uno de los registros contables en los sistemas de información.

El emprendimiento del contador público por asegurar el bien común, dando fe pública y acrecentandola confianza pública, se asemeja a lo que nos dice Cervantes en Don Quijote con su ortografia original de 1605: «Puesto que todo sucediese al rebés de lo que imagino, la gloria de aver emprendido esta hazaña, no la podrá oscurecer malicia alguna" (Cerv. Quij. 2, 41 (fol. 154 vº R. 1. 489 1). + "Prometió [Maritornes] de rezar un rosario, aunque pecadora, porque Dios les diesse buen sucesso en tan arduo y tan christiano negocio, como era el que avian emprendido" (Id. ib. 1.27 (fol. 137 ro; R. I. 3191). Así mismo, el contador ha de estar orgulloso y totalmente embebido en su designio de dar fe pública del bien común, garantizando un registro integro que dé cumplimiento a los ODS.

Dice la página de las naciones unidas, que para superar los desafios globales a los que nos enfrentamos día a día, como la pobreza, la desigualdad, el clima, la degradación ambiental, la prosperidad, la paz y la justicia: y para no dejar a nadie atrás, es importante que logremos cumplir con cada uno de estos objetivos para 2030. 
La prosperidad social es el fin principal del neopatrimonialismo; la búsqueda del equilibrio social como satisfacción plena de las necesidades humanas, a través de las células sociales u organizaciones. En esta concepción, "el patrimonio es una forma de vinculación con el entorno social y ambiental» (Suárez, 2012:152). Nace la pregunta: ¿Cómo se comprende el equilibrio patrimonial de la humanidad, desde el registro contable de las transacciones económicas y sociales?

Las funciones sistémicas del patrimonio, han de ser cubiertas al momento del registro de comprobación contable, en el que se atiendan cada una de ellas, dejando constancia de la comprensión holística de las afectaciones a los ODS. La medición se convierte en el mecanismo de comprensión que se ha de obtener en cualquier registro contable, y que ha de adoptar nuevos modelos contables de medición cualitativa, que le permitan dar cumplimiento a los ODS.

La comprensión de la riqueza en cada comprobante contable, estará influenciada por factores humanos y psicológicos que afectarán el equilibrio patrimonial, pues la naturaleza racional, no percibe, si quiera, la magnificación de la naturaleza del patrimonio para el bien de la humanidad; pues, nunca se ha tomado a éste, como el dador de vida, para la apertura de la conciencia y la creación de una ecuación de armonía estructural que perdura en una eficaz acción social de sostenibilidad garantizada por el contador público como garante del bien común, dando cumplimiento a los ODS.

La ecuación, según Lópes de Sá, está dada en la satisfacción efectiva de la necesidad que se atiende en cada función patrimonial, a través de un registro contable que entra a mediar la ética, la calidad y el aseguramiento de la información para dar cumplimiento a los ODS. Allí, en cada uno de los comprobantes, y con su firma, queda patentado el ser 
contable. Su firma ha de dejar huella del análisis sobre la comprensión holística que pudo observar, evidenciar y revelar sobre el fenómeno, deberá explicar de forma precisay bajo indicadores de eficacia, qué pudo implementar, para el logro de los ODS.

Este nivel de comprensión sobre el fenómeno contable, asegurará un registro íntegro, ético y de alta calidad, para dar fe pública, no sólo del bien común, sino también de la eficacia del ser contable. El plexo rizomático que se configura al momento de firmar la revisión de los comprobantes contables, debe permear toda la estructura administrativa, de gestión, de estrategia y de operación contable, que compruebe y evidencie la fe pública del equilibrio patrimonial, dentro y fuera de la biósfera empresarial. Un equilibrio patrimonial dado por el nivel de cumplimiento de los ODS para mitigar el riesgo de seguir colapsando bajo la hecatombe de la corrupción y la ineficacia social.

\section{Discusión}

La ciencia contable, al igual que a cualquier otra ciencia, no podrá hacernos conocer la naturaleza de las cosas, tan sólo explicar la lógica de las relaciones esenciales del fenómeno contable, y para ello:

Es preciso emplear todos los recursos de la inteligencia, de la imaginación, de los sentidos y de la memoria, lo mismo para tener una intuición distinta de las proposiciones simples, que para comparar convenientemente lo que se busca con lo que se conoce, a fin de descubrirse por este medio, o para encontrar las cosas que necesitan ser comparadas entre sí; en una palabra, no hay que olvidar ninguno de los medios que el hombre puede emplear. (Descartes, c. 1930, p. 306; citado por Lopes de Sá, c. 1981/2, apéndice, p. I). 
La discusión girará en torno a que, como nos enseña Tarski, toda teoría científica es un sistema de proposiciones que se aceptan como verdaderas (1977, p. 25). Será entonces, el desafio que han de superar los contables, para consensuar acuerdos de representación contable que permitan el seguimiento y control de los ODS.

En los juegos lógicos de Lewis Carroll, las proposiciones pueden cumplir distintas funciones: representar los objetos de actitudes, como creencias y deseos; ser una, en múltiples contextos, según los idiomas a que se traduzca; ser susceptible de ser verdadera o falsa, al emitir oraciones declarativas o apofánticas. El bien común ha de ser representado por distintas proposiciones que permitan su comprensión, con el fin de contribuir con la función de eficacia contable, empresarial y social.

\section{Conclusiones}

La primacía de un ser contable empoderado en su papel de dar fe pública, y de generar la confianza en el eficaz cumplimiento del bien común para garantizar la vida en el planeta, le permiten al contador público en ejercicio, encontrar los mecanismos, las fórmulas y los métodos para vincular indicadores tridimensionales de eficacia empresarial, a los indicadores que permitan el logro de los ODS, en todos y cada uno de los hechos o transacciones económicas de las organizaciones tanto públicas como privadas, bajo una ecuación cibernéticamente segura para el cálculo total de la sostenibilidad de la vida.

Las visiones paradigmáticas frente a la aplicación de normas positivistas de la contabilidad, se desvanecen para afrontar amorosamente nuestro propio ser, en el bien del otro; producto de una 
etnografia que utiliza métodos e instrumentos que de forma objetiva, metódica, estadística y tecnológica, satisfagan los requerimientos econométricos y contamétricos de la ecuación contable tridimensional, para el logro de los ODS y la eficacia empresarial.

Los principales actores en la ejecución, dirección y regulación internacional de politicas contables, deberán hacer pública, su disposición y solidaridad institucional, ética y moral, para con la contabilidad; que como disciplina milenaria, ha de repensary representar una realidad tridimensional para el cumplimiento de los ODS.

Las crisis actuales de la humanidad, han afectado el correcto desenvolvimiento científico de la contabilidad en su misión de mantener la ecuación patrimonial para garantizar la sostenibilidad empresarial; sin embargo, a pesar de ello, y por ley, como en el caso de Colombia, la contabilidad es la única y principal herramienta para el seguimiento y control de la eficacia dentro y fuera de las organizaciones. Deberá entonces emanciparse de las ataduras de la ciencia positivista, que no le ha permitido asegurar la sostenibilidad de las empresas, ni de la vida, como el principal patrimonio y capital de la humanidad.

El ser contable crecerá en entornos de formación etnográfica en los que se entrelacen las voluntades, las habilidades, las capacidades y las competencias técnicas, interpretativas, cognitivas y metacognitivas de la comunidad contable para garantizar una práctica ética y de alta calidad, en la aplicación de las normas internacionales de información financiera y no financiera, garantizando la evolución científica de la contabilidad, sobre su objeto de estudio: la eficacia y primacía del ser contable en las organizaciones para cumplir con la ecuación de la sostenibilidad de la vida en el planeta. 


\section{Referencias}

Amézquita Medina, C. (2021). El interés emancipador de la ciencia contable. Un recorrido epistemológico. Revista Científica Arbitrada de la Fundación MenteClara, Vol.6 (230). doi: https:// doi.org/10.32351/rca.v6.230

Cervantes Saavedra, Miguel de (1605/1997). El Ingenioso Hidalgo Don Quijote de la Mancha (edición preparada por Justo García Soriano y Justo García Morales, con 120 grandes composiciones a página entera de Gustavo Doré, además de 48 ilustraciones reproducidas de diversas ediciones nacionales y extranjeras). Madrid: Aguilar S.A. ediciones. Cervantes Saavedra, Miguel de (1979). El Ingenioso Hidalgo Don Quijote de la Mancha (edición preparada por Justo García Soriano y Justo García Morales, con 136 ilustraciones de diversas ediciones nacionales y extranjeras, y cuatro láminas fuera del texto). Madrid: Aguilar

Consejo Regional de Contabilidad de Santa Catarina. (2017). Livro de bolso do profissional da contabilidade. Florianópolis, SC: autor

Einstein, A. (1984). Notas autobiográficas. Madrid: Alianza Editorial.

Franco, R. (2012a). Fiscalización estratégica de arquitectura organizacional. Una tecnología para la revisoría fiscal. Bogotá: Universidad Libre

Franco Ruiz, Rafael Antonio. (2016). Sociodicea contable en evolución: del saber estratégico a la crisis de la representación. Revista Científica General José María Córdova, 14(18), 269-307. Retrieved November 20, 2021, from http:/ / www.scielo.org.co/scielo.php?script=sci_arttext\&opid=S1900$658620160002000148 \% \operatorname{lng}=$ en 8 thlng=es

Franco, R. (2018). Pensamiento contable latinoamericano: entre colonizaciones y resistencias. Revista Científica General José María Córdova, 16(22), 133-161. DOI: $10.21830 / 19006586.325$

García Casella, C. L., Rodríguez de Ramírez, M. C. \& Fronti de García, L. (2001). Elementos para una te oría general de la contabilidad. Buenos Aires: La Ley

Hernando Bermúdez Gómez, "Revisoría fiscal. Órgano social /", -:Ediciones de la U, 2016. Consultado en línea en la Biblioteca Digital de Bogotá (https://www.bibliotecadigitalde bogota.gov.co/resources/2910512/ ), el día 2021-11-20.

Lopes de Sá, A. (1992b). Fundamentos lógicos de la teoria de las funciones sistemáticas del patrimonio hacendal. Cuadernos de Ciencias Económicas y Empresariales, 16(23), 13-45.

Lopes de Sá, A. (2000). Princípios fundamentais de contabilidade. São Paulo: Editora Atlas.

Lopes de Sá, A. \& Lopes de Sá, A. M. (1995). Dicionário de contabilidade. 9. a ed. São Paulo: Atlas.

Lópes de Sá, A. (2019). El filósofo de la Contabilidad. Revista Científica General José María Córdoba, 17(25), 149-175. Recuperado de http://www.scielo.org.co/pdf/recig/v17n25/1900-6586recig-17-25-148.pdf

Lopes de Sá, A. (2000). Prosperidad y el esfuerzo científico del neopatrimonialismo contable para una nueva sociedad. Recuperado de http://antoniolopesdesa.com.br/artigos/internacionais

Lopes de Sá, A. (2000). Princípios fundamentais de contabilidade. São Paulo: Editora Atlas.

Lopes de Sá, A. (1992). Teoria geral do conhecimento contábil: lógica do objeto científico da contabilidade. Belo Horizonte, Brasil: IPAT-UNA.

Lopes de Sá, A. (2010b). Normas internacionais e fraudes em contabilidade: análise, crítica introdutório, geral e específica. Curitiba 
Martínez, G. (2014). Teoría y metodología de la contabilidad. Revista Lúmina, (15), 75-104.

Stevens, C. E. (Ed.). (2003). A contabilidade sob o enfoque neopatrimonialista. Rio Grande do Sul: Editora Unijuí

Suárez Pineda, Jesús Alberto (2012). Benedetto Cotrugli Raugeo: Padre de la gestión moderna

Suárez, J. A. (2014a). En busca de la eficacia social de la representación contable. Una recensión semiótica de la sociedad arcaica a la sociedad capitalista. Teuken Bidikay, 5(5), 55-76.

Suárez, J. A. (2014b). La eficacia social de la representación contable en Lopes de Sá. Criterio Libre, 12(20), 225-246. doi: https://doi.org/10.18041/1900-0642/criteriolibre.2014v12n20.237

Suárez, S. A. (2012). Fundamentos filosóficos científicos de la teoría neopatrimonialista de la contabilidad. Saber, Ciencia y Libertad, 7(2), 145-157. doi: https://doi.org/10.18041/2382$\underline{3240 / \text { saber.2012v7n2.1859 }}$

Tua Pereda, J. (1983). Principios y normas de contabilidad. Instituto de planificación contable, Madrid,h Astete, M. A. (1998). Escritura y lectura crítica de artículos científicos. En R. Burgos Rodríguez (ed.), Metodología de inve stigación y e scritura científica en clínica. Parte IV. Granada: Escuela Andaluza de Salud Pública.

Otras fuentes: Revista e-Ciencias de la Información. Escuela de Bibliotecología y Ciencias de la Información, Universidad de Costa Rica San José 2060, Costa Rica. Tel. (506)2511-1919 - Fax: (506) 25111949 http://revistas.ucr.ac.cr/index.php/eciencias/index 